\title{
The Dominant Educational Discourses Underlying the Cassells Report
}

\author{
Fionnuala Darby \\ School of Business, Institute of Technology Blanchardstown \\ Dublin, Ireland. \\ Daniel McSweeney \\ Department of Informatics, Institute of Technology Blanchardstown \\ Dublin, Ireland. \\ Kathy O'Reilly \\ School of Business, University College Dublin \\ Dublin, Ireland.
}

(C) Author(s). This work is licensed under the Creative Commons Attribution-NonCommercialShareAlike 4.0 International License. To view a copy of this license, visit https://creativecommons.org/licenses/by-nc-sa/4.0/.

\section{Abstract}

The Cassells report "Investing in National Ambition: a Strategy for Funding Higher Education," creates an opportunity to explore critical issues in Ireland's higher education sector. This paper excavates behind the report for discourse, agency, power, influence and environmental factors, to come to understand the assumptions made in the document. $A$ document is always situated within a social setting and context. By considering this setting we attempt to unearth the dominant educational discourses in the document. Some of these discourses are obvious and substantial, others are muted and unrevealed. This paper provides insights to assist educators to develop new understandings of the ways in which policy documents are used in the context of the Cassells report.

NOTE: The authors are currently registered on the Doctorate of Education Programme at Maynooth University with the Department of Higher and Adult Education. They would like to acknowledge the support of Professor Anne Ryan and Dr. Bernie Grummell at Maynooth University where the foundations for this paper began.

\section{INTRODUCTION}

Our efforts to view the document from multiple perspectives highlight issues that are not being considered in the Cassells report. In excavating the educational discourses in the report, the politics of valid and reliable knowledge created by a few come into prospect and can determine policy, leaving many uninformed and uninvolved. Sustainability in higher education requires a much longer timeframe than policy makers can generally give to it. Sustainability requires thinking not only one budget or general election ahead, but thinking one generation ahead. We pay particular attention to the contextualisation of the report and focus on six key educational discourses with the aim of promoting debate on policy in higher education. 


\section{CONTEXTUALISATION OF THE POLICY: THE SOCIO-POLITICAL CONTEXT}

According to Prior, "the content of a document is never fixed or static, not least because documents have always to be read, and reading implies that the content of a document will be situated rather than fixed," (2003, p. 4). The Cassells report is situated in a time of crisis and political upheaval. When the report was published in July 2016, a Fine Gael-led minority government entered into coalition, supported by Fianna Fáil, bringing about a new political landscape in Ireland.

Sustainable efforts in higher education policy require suitable timeframes and political stability, neither of which are a given in the current political landscape. The Cassells report proposes three alternative funding options which are to some degree unpalatable across the current political domain. However, what appears initially politically toxic may not seem so when we have had time to digest the information that is being presented in public domains. Despite the presence of three proposed funding models, the report has managed to shift the debate in both government circles and the media towards funding higher education through income contingent loan schemes (ICLs). The idea that the student should pay has become a dominant discourse, leading to a possible legitimisation of policy by adopting ICLs for the payment by the citizen for use of public services. Chapman and Dorris (2016) describe the Australian experience, where income contingent loan schemes have become public policy for drought relief, low-level criminal fine repayments and penalties for insider trading and collusion.

While the 'student must pay' discourse gains prominence in the public arena, the discourse of who currently pays is muted and hidden. A striking point in the report is that $50 \%$ of the 210,000 students in Ireland do not pay the current student contribution charge of $€ 3000$. When describing a discourse Ryan offers some guiding questions when engaging in discourse analysis: "What conditions facilitate or militate against a discourse being widely circulated?" (in press, p. 5). While deeper excavation is required to understand why $50 \%$ of students do not pay the student contribution charge, it is noteworthy that capital assets are not assessed in the eligibility criteria for accessing financial assistance to go to college, thereby excluding some sections of society from paying the student contribution ${ }^{1}$. The discourse of 'who pays' is closely linked to the discourse of higher education as a public good. Viewing higher education as a public good "is in constant tension with government policies of commercialisation and reinforcement of inequity," (Connell, 2016, p. 70).

\section{IDENTIFICATION OF KEY PLAYERS: AN ANALYSIS OF THE STAKEHOLDERS}

The Cassells report is currently being debated in policy fora comprising those from a university background. In addressing the Joint Committee on Education and Skills in November 2016, the then interim CEO of the Technological Higher Education Association (THEA), Professor Tom Collins, noted that staff in the higher education sector mostly received their qualifications from a university (Joint Committee on

\footnotetext{
${ }^{1}$ Student Universal Support Ireland (SUSI) https://susi.ie/eligibility/income/
} 
Education and Skills, 2016). The consensus view of these committees is then brought to the Minister for Education and Skills. How this influences the debate and decision-making depends on the discourse used to "interpret and filter" the concept, (Ryan, 2006: 22). According to Ryan "the concept of discourse shows how the fixing of meaning is never a neutral act but always privileges certain interests," (2006, p. 24). By analysing the positions adopted of those debating the report vis-à-vis the field of power we gain an insight into the interests and values that are served or not. The discursive climate in the sector is identified below to understand the influence and power they may or may not exert.

Currently the Irish universities sector is advocating the funding of higher education through the introduction of ICLs that reflect the earnings potential of the graduate, (Joint Committee on Education and Skills, 2016). While this sector views ICLs as equitable, affordable and allowing widening participation from lower socio-economic groups, Professor Andrew Deeks, President, UCD, notes that the university sector places significant weighting on international rankings, thereby justifying an increase in fees and a lucrative income stream for the university, (Joint Committee on Education and Skills, 2016).

The Institutes of Technology account for $38 \%$ of all higher education graduates in Ireland. THEA is advocating higher education to be free at the point of entry and exit up to and including the Level 7 award on the National Framework of Qualifications (NFQ) standard. According to Professor Ciarán Ó Catháin, President, Athlone Institute of Technology, the cost of this is to be funded by the Exchequer, (Joint Committee on Education and Skills, 2016). In addition, the sub-sectoral impact of any intervention is under-represented in the report. An Irish Times analysis of student enrolments for 2016 show that the number who rely on grants to go to college is significantly higher in Institutes of Technology, especially in regional areas, (O'Brien, 2017).

The Union of Students in Ireland (USI, 2016) makes the case for publicly funded higher education. The USI is not in favour of ICLs, (USI, 2016). We struggle to hear their voice or that of their parents or guardians in the media, resulting in educational institutions having stronger voices than the learners on this occasion.

\section{A DISCOURSE OF CRISIS}

The report opens with a discourse of crisis in which Ireland is portrayed as transitioning out of a 'deep crisis'. The crisis has impacted on higher education following years of funding cuts and self-sacrifice. This discourse of crisis is in part supported by the Irish Higher Education Authority which in 2011, driven by a wider narrative of public service reform, published the 'National Strategy for Higher Education to 2030' (HEA, 2011). The report aimed to redefine the structure of Irish higher education and the relationship between it and the state. It presents higher education as a 'cure and restorative' for the collapse of the Irish economy and suggested a redefinition of the mission of higher education, conditioned by economic demands and the short-term need to overcome the economic crisis. It acknowledged the human capital paradigm in its justification for widening participation while reinforcing the concept of Ireland's knowledge economy (Walsh and Loxley, 2015). This surrounding narrative permeates the Cassells report, which itself places an 
emphasis on the economic importance of education and a paralleled reforming of the surrounding economic model. Education is positioned as an 'enabler', capable of lifting us away from the crisis. The sense of crisis is used to validate a discourse of underfunding across the sector. Underfunding is framed as a core crisis, the effects of which will impact on the students, the institutions and the goals of the state.

\section{A DISCOURSE OF CONTROL, OVERSIGHT AND THE RIGHT EDUCATION}

O'Connor $(2014$, p. 4) suggests that higher education is a site for power struggles and the outcome of such power struggles can influence the shape and purpose of higher education both nationally and internationally. A discourse of power of control is suggested in the proposal of a 'Virtuous Circle of Investment, Quality and Verification', which frames funding as an investment by the state. The report states that 'institutional autonomy remains a core tenet of national policy' yet it appears that autonomy must be exercised in a manner which matches the strategic priorities of the state and the market. 'Incentive mechanisms' to drive 'national objectives' point towards increasing state influence over institutions, their decision-making and their provision. The report suggests that funding allocations should be weighted towards "strategically important and vulnerable provision". If there are courses which are 'strategically important', then there may be courses that are 'unimportant' or not worthwhile. Courses which fail to meet the requirements of stakeholders risk removal from this virtuous circle of investment.

The justification for power over provision is suggested through the discourse of worthwhile education. Higher education is charged with the responsibility of producing human capital with the 'right' skills to meet the needs of the economy. These right skills are highlighted in various government reports including National Skills Strategy 2025 (Department of Education and Skills, 2016), Innovation 2020 (Interdepartmental Committee on Science, Technology and Innovation, 2015), What Do Graduates Do? The Class of 2014 (HEA, 2016). The latter report suggests that graduates should 'do' something to be of value and this doing should be categorised within the context of the wider economic system. This supports a narrative that those who are 'doing' have engaged with a worthwhile form of education which has provided the right skills to enable one to do something. Thus graduates fit the template of the 'rational economic actor' (REA) citizen (Lynch, Lyons and Cantillon, 2007), an economic citizen of greater value than the cultural or politically engaged citizen.

The muted discourse of the responsible citizen is highlighted by the contrast between those that are 'doing' and those that are not. Those that are 'doing' are framed as 'responsible citizens' (Fejes, 2010). The responsible citizen is constructed as responsible for her/his own employability, and the state and the employer are construed as enablers. Thus a theme of 'responsibilising of the self' (Peters, 2001) emerges, a theme associated with a new tendency to 'invest' in the self. Giroux argues that the market-driven student engages in education for the self, focusing on the demands of the market while "intellectual ambitions are often reduced to an instrument of the entrepreneurial self" (2002, p. 426). 


\section{INTERNATIONAL COMPARATORS: HOW ARE THEY SELECTED?}

Key figures are often used as a mode of legitimisation in a document to gain support for the claims that the authors make. The Cassells report is no exception to this. If the statistics and quants are isolated from the report, Australia is the only southern hemisphere country mentioned - once again reinforcing Santos' normalisation of the right of the North as possessing "good" knowledge, (Santos, Nunes and Meneses, 2007). There are a number of international comparators in relation to funding models for higher education. The selection of comparator countries in the Cassells report can be called into question, as there is no clear justification as to why those particular countries were chosen. Some of the selected comparator countries, such as Germany, have considerably different scales of economies and populations to that of Ireland. Countries which have not been selected for comparison, such as Portugal, Norway and Denmark, have similar demographic and economic characteristics and are often used as Ireland's comparators in other contexts, (Marginson, 1997)

The structure of higher education and the impact of higher education funding models in these comparator countries is also worthy of consideration, yet it is excluded from the report. Research into funding models in Portugal, Denmark and Norway (Frølich, Kalpazidou Schmidt and Rosa, 2010) indicates that all funding models will have an impact on the perceived role and value of academia. This type of consideration is conspicuously absent from the Cassells report. Furthermore, like Ireland, all three countries have seen a significant policy shift in higher education funding, moving toward mixed models that include:

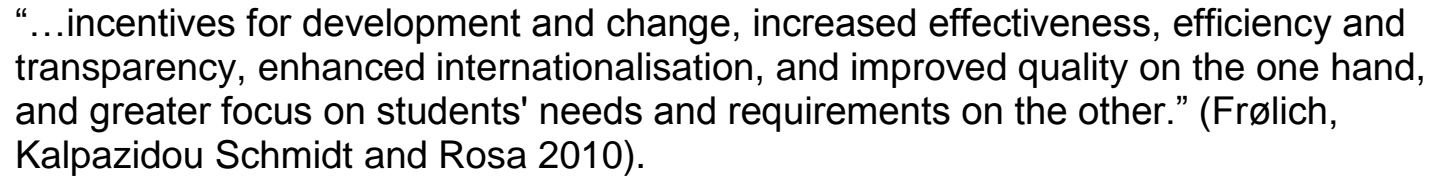

"... incentives for development and change, increased effectiveness, efficiency and transparency, enhanced internationalisation, and improved quality on the one hand, and greater focus on students' needs and requirements on the other." (Frølich, Kalpazidou Schmidt and Rosa 2010).

In examining funding models, the Cassells report fails to acknowledge the diversity of Ireland's higher education institutions and the impact that these models may have on institutions. Studies such as those carried out by Liefner (2003) and Jongbloed and Koelman (2000) suggest that changes in funding will impact on the behaviour of higher educational institutions as well as on their internal processes of resource allocation. Changes in behaviour manifest in institutional focus on 'performativity, as evidenced by the emergence of an emphasis on measured outputs: on strategic planning, performance indicators, quality assurance measures and academic audits'. (Olssen and Peters, 2005).

The Cassells report suggests a one-size-fits-all funding model and ignores differences in mission, regional objectives, student cohorts, graduate profiles, research funding, ranking, overheads and scale. The differences absent from the report are highlighted by Johnes (1996), who argues that higher education institutions are multi-product organisations with multiple objectives, lacking consensus with regard to objectives, input and output. Given such diversity, there is little agreement regarding the appropriate method of evaluating and assessing such institutions. Hence, a one-size-fits-all approach to funding is inadequate. 


\section{THE DISCOURSE OF CURATIVE EDUCATION}

The report advances that underfunding is a cause of social class gradients and issues of participation. While universities argue for greater funding to combat social inequality, Lynch suggests that universities are embedded with social interests, doing little to "challenge the evident social closure practices within powerful professional groups," (2006, p. 2). The report suggests that many of these current issues in higher education will be remedied by increased funding, supporting the view that the current uses of funding are appropriate, well-managed and fit for purpose. Carpentier (2010) argues that these approaches to funding, while intending to increase access, tend to benefit those socio-demographic groups who are already among the most well-represented in higher education:

"Despite these impressive levels of public investment, persistent patterns of underrepresentation continue to present a challenge to policymakers and universities, and this under-representation is likely to be exacerbated by the substitution of public funds with private individual fees (Carpentier, 2010)" (quoted in Burke, 2013).

This underlying discourse of what one might call 'curative education' is the belief that there is a model of higher education financing that will be the panacea for problems of higher education access and participation, while still balancing the economic interests of public policy makers, is clearly interwoven throughout the Cassells report.

\section{CONCLUDING THOUGHTS}

Written during a time of great economic and political upheaval the Cassells report aims to highlight the future funding needs of higher education and suggests ways by which these needs may be met. The document appears to be influenced by neoliberalism, described by Giroux (2002, p. 425) as 'the defining economic paradigm of our time'. While acknowledging education as a public good, it connects much of this 'good' to market and economic needs, linking the provision of education to the strategic needs of the market and state. Students are portrayed as responsible citizens (Fejes, 2010), charged with the selection of courses which will meet the needs of a variety of stakeholders, including the state and market. Autonomy over provision is threatened by a new proposed funding model and a threat to academia is made through questioning the status of contracts, proposals of targeted redundancies and suggestions around the use of employment control frameworks.

This neoliberal approach is legitimised through a discourse of crisis. The authors continually remind the audience of the economic and political crisis which threatens the country. Education is framed as a solution to that crisis but reformation is required if the crisis is to be overcome. It is worth noting that at the time of writing, few of the recommendations of the report have been implemented. Continued political uncertainty has bred a culture of inaction, and while decision-making may be hidden from public view, the discourses within the document remain. The document continues to be a site of struggle, the outcomes of which may shape our higher education system for generations. 


\section{References}

Burke, P.J. (2013) 'The right to higher education: neoliberalism, gender and professional mis/recognitions', International Studies in Sociology of Education, 23(2), pp. 107-126.

Chapman, B. and Dorris, A. (2016) Modelling Higher Education Financing Reform for Ireland. Working Paper Series, N271/16. Department of Economics, Finance and Accounting: Maynooth University.

Connell, R. (2016) 'What are good universities?', Australian Universities' Review, 58(2), pp. 67-73.

Department of Education and Skills (2016) National Skills Strategy 2025 - Ireland's Future. Available at:

https://www.education.ie/en/Publications/Policy-

Reports/pub national skills strategy 2025.pdf (Accessed: 7 February 2017).

Fejes, A. (2010) 'Discourses on employability: constituting the responsible citizen', Studies in Continuing Education, 32(2), pp. 89-102.

Frølich, N., Kalpazidou Schmidt, E. and Rosa, M.J. (2010) 'Funding systems for higher education and their impacts on institutional strategies and academia: a comparative perspective', International Journal of Educational Management, 24(1), pp. 7-21.

Giroux, H. (2002) 'Neoliberalism, corporate culture, and the promise of higher education: the university as a democratic public sphere', Harvard Educational Review, 72(4), pp. 425-464.

Higher Education Authority (2011) National strategy for higher education to 2030, Dublin: HEA, Available at:

http://hea.ie/assets/uploads/2017/06/National-Strategy-for-Higher-Education-2030.pdf (Accessed: 7 February 2017).

Higher Education Authority (2016) What Do Graduates Do? The Class of 2014. Available at: http://hea.ie/assets/uploads/2017/06/What-Do-Graduates-Do-The-Class-of-2014-1.pdf (Accessed: 7 February 2017).

Interdepartmental Committee on Science, Technology and Innovation (2015) Innovation 2020. Available at:

https://www.djei.ie/en/Publications/Publication-files/Innovation-2020.pdf (Accessed: 7 February 2017).

Johnes, J. (1996) 'Performance assessment in higher education in Britain', European Journal of Operational Research, 89(1), pp.18-33.

Joint Committee on Education and Skills Debate, Dáil Éireann, 10 November 2016.

Available at:

http://oireachtasdebates.oireachtas.ie/debates\%20authoring/DebatesWebPack.nst/committe etakes/ESJ2016111000002?opendocument\#C00100 (Accessed: 9 January 2017).

Jongbloed, B. and Koelman, J. (2000) 'Vouchers for higher education? A survey of the literature', Study commissioned by the Hong Kong University Grants Committee. Enschede: CHEPS.

Liefner, I. (2003) 'Funding, resource allocation, and performance in higher education systems', Higher Education, 46(4), pp. 469-489. 
Lynch, K. (2006) 'Neo-liberalism and marketisation: the Implications for higher education', European Educational Research Journal, 5(1), pp. 1-17.

Lynch, K., Lyons, M. and Cantillon, S. (2007) 'Breaking silence: educating citizens for love, care and solidarity', International Studies in Sociology of Education, 17(1-2), pp. 1-19.

Marginson, S. (1997) Markets in education. Sydney: Allen \& Unwin.

O’Brien, C. (2017) 'New figures expose class divide in higher education', The Irish Times, 7 February [Online]. Available at:

http://www.irishtimes.com/news/education/new-figures-expose-class-divide-in-highereducation-1.2965895 (Accessed: 7 February 2017).

O'Connor, P. (2014) Management and gender in higher education. Manchester: Manchester University Press.

Olssen, M. and Peters, M.A. (2005) 'Neoliberalism, higher education and the knowledge economy: from the free market to knowledge capitalism', Journal of Education Policy, 20(3), pp. 313-345.

Peters, M. (2001) 'Education, enterprise culture and the entrepreneurial self: a Foucauldian perspective', Journal of Educational Enquiry, 2, pp. 58-71.

Prior, L. (2003) Using Documents in Social Research. New Delhi, India: SAGE Publications.

Ryan, A. (in press) 'Discourse: some considerations for the reflective practitioner'.

Ryan, A. (2006) 'Post-positivist approaches to research' in Researching and writing your thesis: a guide for post-graduate students. MACE: Maynooth Adult and Community Education, pp. 12-26.

Santos, B., Nunes, J. and Meneses, M. (2007) 'Opening up the cannon of knowledge and recognition of difference', in Santos, B. (ed.) Another knowledge is possible: beyond northern epistemologies. London: Verso, pp. xix-lxii.

Union of Students in Ireland (2016) Position paper on the funding of higher education. Available at:

http://usi.ie/wp-content/uploads/2016/12/FINAL-FINAL-USI-Position-Paper-on-the-Fundingof-Higher-Education-2016.pdf (Accessed: 7 February 2017).

Walsh, J. and Loxley, A. (2015) 'The Hunt Report and higher education policy in the Republic of Ireland: 'an international solution to an Irish problem?", Studies in Higher Education, 40(6), pp. 1128-1145. 